\title{
Imaging Extended Defects by TEM
}

\author{
C. Barry Carter ${ }^{1-3}$ \\ ${ }^{1}$ Dept of Chemical \& Biomolecular Engng, U. of Connecticut, 191 Auditorium Road, Storrs, CT 06269 \\ ${ }^{2}$ Dept of Materials Science \& Engng, U. of Connecticut, 97 North Eagleville Road, Storrs, CT 06269 \\ ${ }^{3}$ Institute of Materials Science, U. of Connecticut, 97 North Eagleville Road, Storrs, CT 06269
}

In this invited talk, I will suggest where we are in our use of TEM for imaging extended defects and guess where we are going. Since the topic of this Symposium concerns advances in imaging and quantification of strain, local atomic structure, and the chemistry of extended defects, the present talk will emphasize the history and development of diffraction contrast methods for the analysis of extended defects in the TEM but must also include a discussion of the use of high-resolution imaging techniques. Examples will be presented from my group's work on metals, semiconductors and ceramics with a discussion of the factors that have limited our understanding of these defects and those that continue to limit our ability to improve this understanding.

Several specific topics will be mentioned not necessarily in the following order, although the first topic should always be specimen preparation. How we make the specimen can affect not only what we see but can even change the geometry of the defect we wish to study. Illustrations of defects that are not so susceptible to such changes will also be considered.

The second topic will be the advantages and limitations of using the weak-beam dark-field imaging technique versus high-resolution (HRTEM) imaging. What do we gain and what do we lose and why isn't the WB technique used more widely? The latter question has much to do with the third broad topic of improving resolution, correcting $\mathrm{Cc}$ and $\mathrm{Cs}$, and using a monochromated electron beam. If we are able to consider the latter then we must extend our discussion to include modeling the defect, simulating the image and comparing simulated images with those obtained under well-defined experimental conditions.

As examples, I will discuss some special grain boundaries as illustrated by two well known examples ([1-3] from an Mg-Al spinel that are shown in Figure 1 and consider how modern imaging can improve our understanding of such defects. These two examples are chosen because in both cases the defects are constrained to lie along particular directions, which is essential for the interpretation of HRTEM images. The next example is the faulted dipole, which again must lie along a particular direction [4]. That property makes it ideally suited to HRTEM imaging and can provide information about defects and bonding in compound semiconductors that no other defect provides. The final example shown here concerns the motion of jogs along individual dislocations [5]. The method used to image these defects in the WB technique-i.e., diffraction contrast. Like the dislocations themselves, of course, we are not seeing the jogs, just the effect of the jog. The rest is image interpretation.

In each case, modern TEMs have the potential to make large improvements to our understanding of extended defects but the limitations must be understood, so I will conclude with a little philosophy.

\section{References:}

[1] Carter, C.B., Elgat, Z. and Shaw, T.M., 1987, Philos. Mag. A55(1), 21-38. 'Lateral Twin Boundaries in Spinel.' 
[2] Wendt, H., Ostyn, K.M. and Carter, C.B., 1984, Mater. Res. Soc. Symp. Proc. 24, 87-92.

'Dislocation Dissociation in $\mathrm{Mg} 0 . \mathrm{nAl}_{2} \mathrm{O}_{3}$ Spinels.'

[3] Ostyn, K.M., Wendt, H. and Carter, C.B., 1983, Beitr. Elektronenmikroskop. Direktabb. Oberfl. 16, 225-232. 'Low-Angle Boundaries in Spinel.'

[4] De Cooman, B.C. and Carter, C.B., 1988, phys. stat. sol. (a) 112, 41-54. 'The Formation of Faulted Dipoles in Plastically Deformed GaAs.'

[5] Carter, C.B. and Hirsch, P.B., 1977, Philos. Mag. 35(6), 1509-1522. 'The Formation and Glide of Jogs in Low Stacking-Fault Energy Face-Centered Cubic Materials.'

[6] Thanks to Sandia National Laboratory where CBC is a CINT Distinguished Affiliate Scientist, and to Doug Medlin, Jim Ciston and Yoosuf Picard for the invitation to present this work. Personal thanks to my former group members and many collaborators (who are listed on the web site www. CBarryCarter. com). Special thanks go to Grant Norton and Dave Williams, co-authors of our two textbooks.

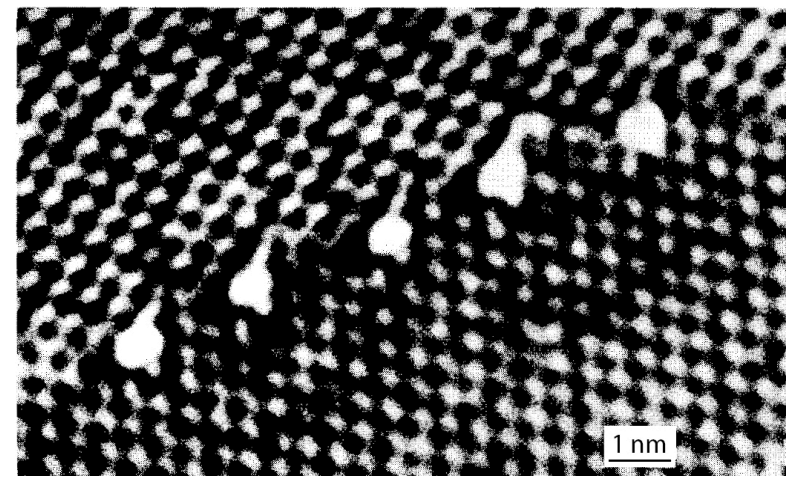

a
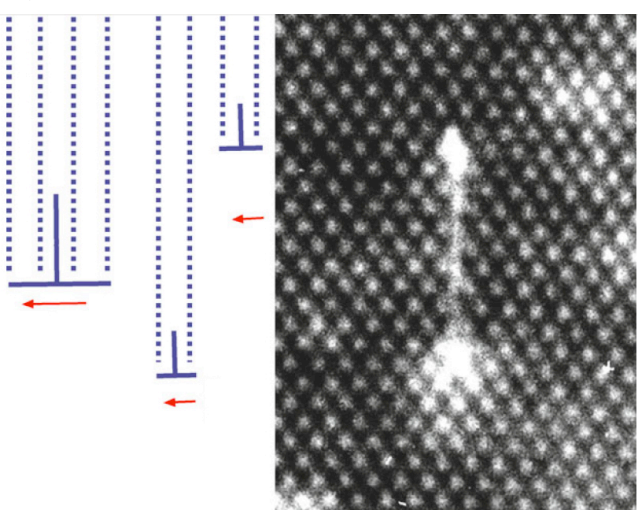

b

Figure 1. HRTEM images of a) a twin boundary and b) a dissociated dislocation in an Mg-Al spinel. The schematic in ' $b$ ' explains that the defect is actually a single dislocation that has dissociated into two partial dislocations by a climb process.

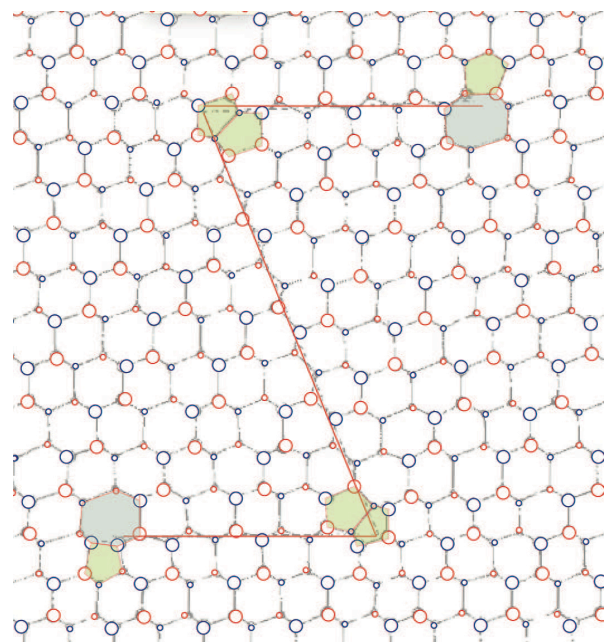

Figure 3 (right). Weak-beam images of jogs moving by climb along a dissociated dislocation in a $\mathrm{Cu}$ alloy. The sample was held at $320^{\circ} \mathrm{C}$ during the observation period. The two pairs of jogs labeled ' $\mathrm{B}$ ' and ' $\mathrm{C}$ ' self annihilate.
Figure 2 (left). A schematic of a faulted dipole of the kind seen in metals such as $\mathrm{Ni}$ and $\mathrm{Cu}$, and semiconductors such as $\mathrm{Si}, \mathrm{Ge}$ and in GaAs.

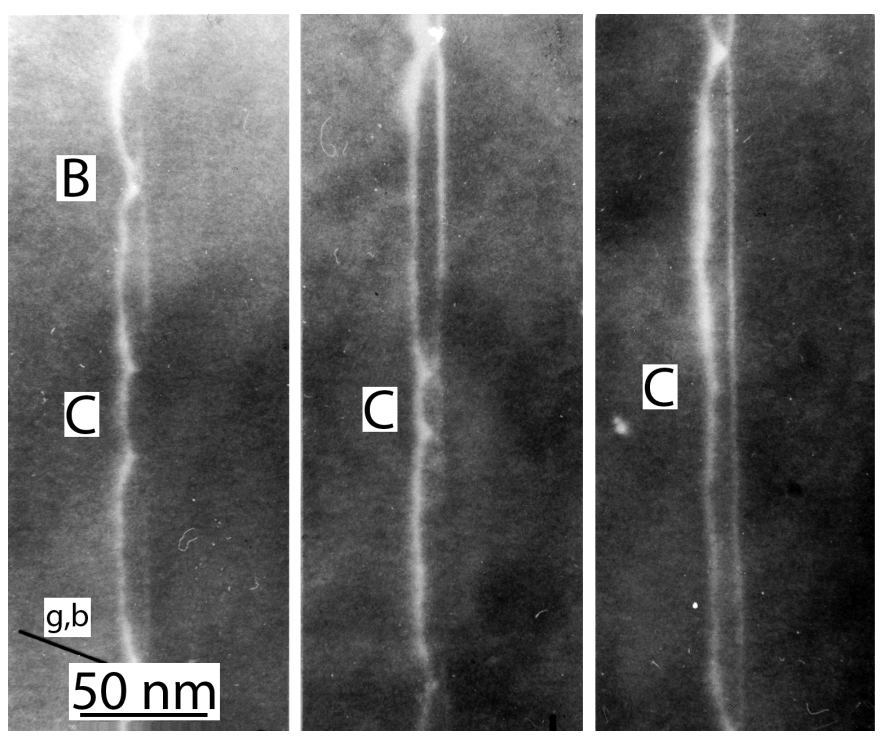

